\title{
Gynaecological laparoscopy courses in the United Arab Emirates
}

\author{
Elbiss $\mathrm{HM}^{1}$, George $\mathrm{S}^{1}$, Sidky I ${ }^{1}$, Abu-Zidan $\mathrm{FM}^{2}$
}

1. Department of Obstetrics and Gynaecology, College of Medicine and Health Sciences UAE University, Al Ain, UAE

2. Department of Surgery, College of Medicine and Health Sciences UAE University' Al Ain, UAE

\begin{abstract}
Background: Laparoscopic surgery is important for gynaecological practice and became the method of choice for many gynaecological procedures having advantages over open surgery.

Objective: To report our modified teaching methods, and evaluation of the gynaecological laparoscopy courses in United Arab Emirates.

Methods: Fifty five participants attended four 3-full day comprehensive hands-on gynaecological laparoscopic skills courses. Non-expensive dry/wet models have been developed for teaching. All participants were evaluated at the end of the course through MCQs and practical laparoscopic exercises. All participants filled out a questionnaire reflecting their opinion on various aspects of the course at its completion. Ethical approval has been received by Research and Ethics Committee of $\mathrm{Al}$ Ain Medical District, Al-Ain, UAE.

Results: Fourteen participants had no laparoscopic experience, 35 had experience at level I and six had experience at level II. There was a statistically significant difference of the MCQ mark between the three levels of experience ( $p=0.05$, Kruskal Wallis test) but not for the practical part, $\mathrm{p}=0.9$, Kruskal Wallis test). The courses were highly valued having an overall average rating of 3.8 out of 4 .

Conclusions: A multimodality non expensive course for teaching gynaecological laparoscopy was highly successful in United Arab Emirates. Models used may be useful for training gynaecological laparoscopy in developing countries. The long term effects of our courses on clinical practice have yet to be evaluated.
\end{abstract}

Key words: gynaecological laparoscopy, skills, training, assessment African Health Sciences 2013; 13(2): 393 - 401http://dx.doi.org/10.4314/ahs.v13i2.28

\section{Introduction}

Laparoscopic surgery is important for gynaecological practice and became the method of choice for many gynaecological procedures having advantages over open surgery. ${ }^{1}$ It requires psychomotor skills different from those needed for open surgery including camera navigation, appreciation of depth and orientation using two dimensional screen, hand brain coordination and force needed to handle the tissues. ${ }^{2}$ It is essential to use both didactic learning and practical sessions to train gynaecologists. Hence, laparoscopic skills simulation programs first need to define the skills that are essential for minimally invasive surgical procedures. This will help improve the clinical practice. ${ }^{3}$

Trainer box, animal models and dry labs have been used to train gynaecologists. Animal
*Corresponding author:
Professor Fikri Abu-Zidan
Department of Surgery
Faculty of Medicine and Health Sciences
P O Box 17666
Al-Ain, United Arab Emirates
E-mail: fabuzidan@uaeu.ac.ae

models are ideal for laparoscopic training. Nevertheless, their use may be restricted due to ethical and religious considerations. Trainer boxes are cheap, accessible and allow controlled training to achieve adequate learning curves for different laparoscopic skills. ${ }^{4}$

Only a few gynaecologists in United Arab Emirates practice laparoscopic gynaecological surgery. Therefore, there is a great need to train gynaecologists to reach different levels of skills in gynaecological laparoscopy. Understanding these needs, we ran four courses of gynaecological laparoscopy during the period of 2008-2011. These courses were accredited by the European Society of Endoscopic surgery.

We aimed to report our modified teaching methods, and evaluation of the gynaecological laparoscopy courses so as to encourage colleagues from other developing countries to run such courses.

\section{Methods}

Four courses of laparoscopic gynaecology were held during the period from 2008 to 2011 at the Faculty 
of Medicine and Health sciences, United Arab Emirates University, each of them lasting 3 full days. Our courses were accredited by the European Society of Endoscopic surgery.

\section{Study participants}

Participants with different levels of experience attended these courses. Classification of experience was based on the Royal College of Obstetricians and Gynaecologists definition of the level of skills required during laparoscopic procedures from 1 (e.g. diagnostic laparoscopy) to 4 (e.g. incontinence reconstruction). ${ }^{5} 13$ participants attended the first course and there were 14 participants in each of the subsequent courses.

\section{Course curriculum}

Table 1 describes the theoretical component of the course which was held in the morning of the first day of the course. The participants were given a booklet with the lecture contents.

The practical demonstration of the course consisted of four sessions, each lasting 4 hours. The sessions included dry and wet laboratory, live surgery on goats to practice different operative skills, and live surgery demonstration on patients.

\section{Table 1: Theoretical content of the laparoscopy course}

\begin{tabular}{|c|c|c|}
\hline \multicolumn{3}{|c|}{ Time (min) Content } \\
\hline 1. Introduction & 15 & Objectives and general overview of the course \\
\hline 2. Introduction to the laparoscope & 30 & $\begin{array}{l}\text { History, terminology, laparoscopic equipment, credentialing guidelines, } \\
\text { raining, physiologic considerations and basic operative technique }\end{array}$ \\
\hline $\begin{array}{l}\text { 3.Laparoscopic ectopic pregnancy } \\
\text { and ovarian cystectomy }\end{array}$ & 30 & $\begin{array}{l}\text { Explaining the role and different techniques of laparoscopy in managing } \\
\text { ectopic pregnancy and ovarian cystectomy }\end{array}$ \\
\hline $\begin{array}{l}\text { 4. Role of laparoscopy in gynaeco } \\
\text { logical emergency }\end{array}$ & 30 & $\begin{array}{l}\text { Requirement, feasibility, efficacy, safety, advantage and disadvantage in } \\
\text { comparison to open surgery. }\end{array}$ \\
\hline 5. Laparoscopy entry & 30 & $\begin{array}{l}\text { Explaining the different laparoscopic entry techniques, advantage and } \\
\text { disadvantage of them, possible complications and their precautions. }\end{array}$ \\
\hline 6. Two-hands utilization in laparoscopy & $\begin{array}{l}\mathrm{E} \\
(2 \\
\text { th }\end{array}$ & $\begin{array}{l}\text { Explaining camera navigation, depth and orientation using two dimensional } \\
\text { 2D) screen, hand brain coordination and the level of force needed to handle } \\
\text { he tissues. }\end{array}$ \\
\hline
\end{tabular}

Dry laboratory consisted of multiple tasks including placing colourful button-shaped candies (small shiny chocolate buttons with crisp coat of primary colours) in circles (figure 1), performing laparoscopy resection of endometriosis (figure 2) (The participants were requested to use laparoscopic scissors to excise the red spots, which represent endometriosis, without

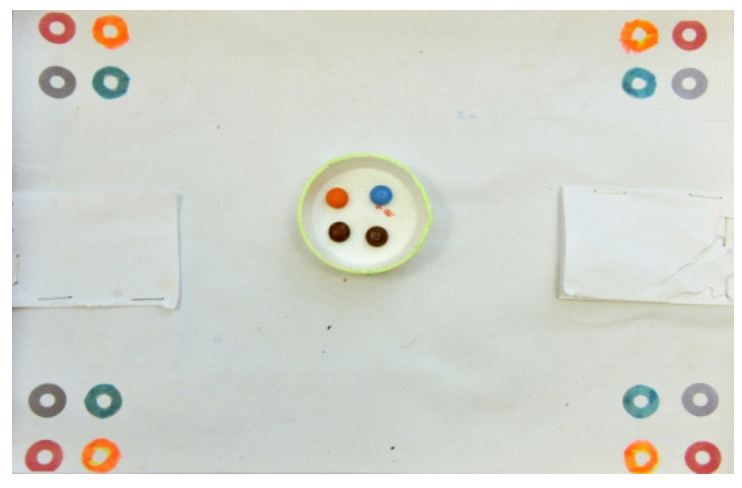

Figure 1: Colourful button-shaped candies with different colours have to be placed in 4 matching circles in 4 corners to teach navigation removing the area around it), doing tubal ligation, performing ovarian cystectomy, and performing laparoscopic salpingectomy using virtual reality (table 2). Participants were initially oriented to equipments such as veress needle, trocars, different telescopes, camera, forceps, scissors and laparoscopic bags.

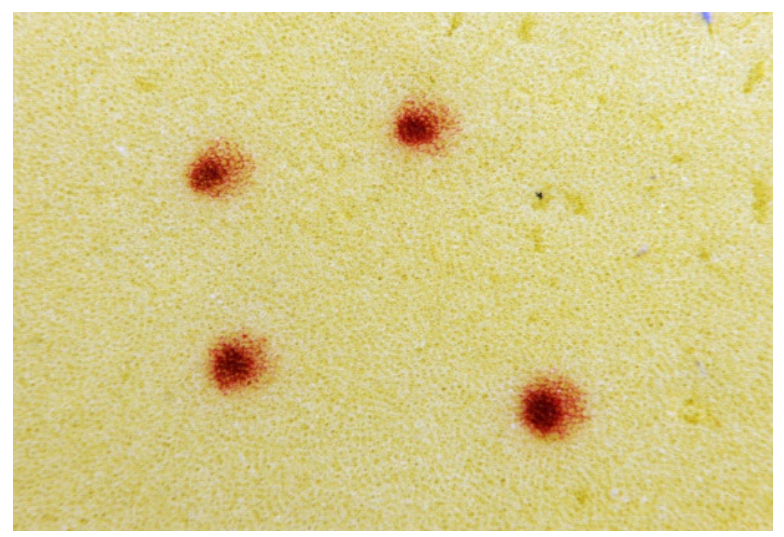

Figure 2: Red spots drawn on sponge to simulate endometriosis 
Table 2: Details of practical sessions (dry lab)

\begin{tabular}{|c|c|c|}
\hline Practical station & Objectives & Task \\
\hline $\begin{array}{l}\text { Colourful button } \\
\text {-shaped candies }\end{array}$ & $\begin{array}{l}\text { To learn camera navigation, appreci- } \\
\text { ation of depth and orientation using } \\
\text { two circles dimensional screen and } \\
\text { hand brain coordination }\end{array}$ & Placing colourful button-shaped candies in \\
\hline Endometriosis & $\begin{array}{l}\text { To learn how to remove or } \\
\text { cauterize red dots drawn on sponge } \\
\text { object using scissors and electrodiathermy } \\
\text { without damaging surrounding tissue }\end{array}$ & Resection of endometriosis \\
\hline Tubal ligation & $\begin{array}{l}\text { To learn how to apply Filshie clip } \\
\text { correctly on fallopian tube }\end{array}$ & Applying Filshie clip \\
\hline Ovarian cyst & $\begin{array}{l}\text { To learn the technique of performing } \\
\text { cystectomy without rupturing the } \\
\text { balloon filled with water. }\end{array}$ & Ovarian cystectomy \\
\hline Virtual reality & $\begin{array}{l}\text { To learn laparoscopic coordination, } \\
\text { tissue "grasping and lifting" and "mani- } \\
\text { pulation and diathermy," "camera and } \\
\text { instrument navigation" }\end{array}$ & Salpingectomy for ectopic pregnancy \\
\hline
\end{tabular}

Virtual reality simulator provided the trainees with instant feedback on time, bleeding, hand placement and amount of pressure used, and cutting of uncoagulated arteries.

For the tubal ligation station, we created a uterine model using balloon filled with sponge and passing a Foley's catheter through the upper part of the uterus (figure 3). Participants were asked to perform tubal ligation by applying Filshie clip on each side of a Foley's catheter using Filshie clip's applicator.

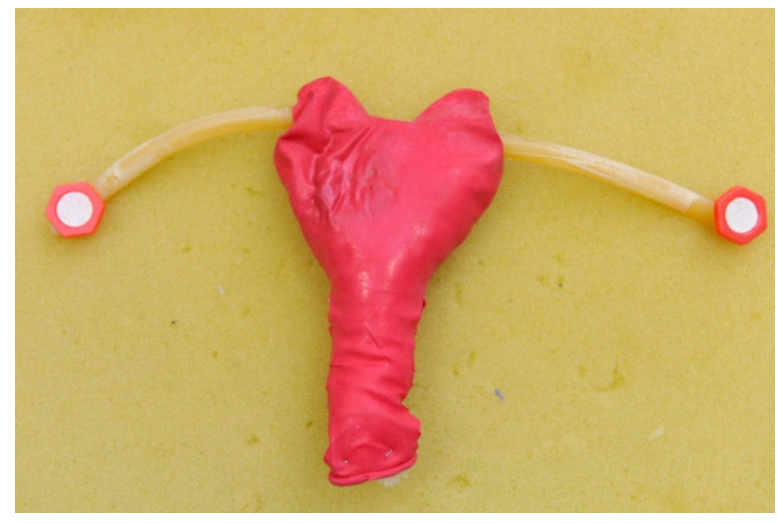

Figure 3: Uterus simulated as balloon filled with sponge with a Foley's catheter going through the upper part of the uterus
The ovarian cystectomy task was performed on a balloon filled with water, which acted as an ovarian cyst. This water filled balloon was placed inside another balloon to depict the ovarian tissue (figure 4). Participants were asked to use laparoscopic scissors to open the outside balloon in order to peal it off from the inside balloon, which was filled with water, without rupturing the balloon that contains water.

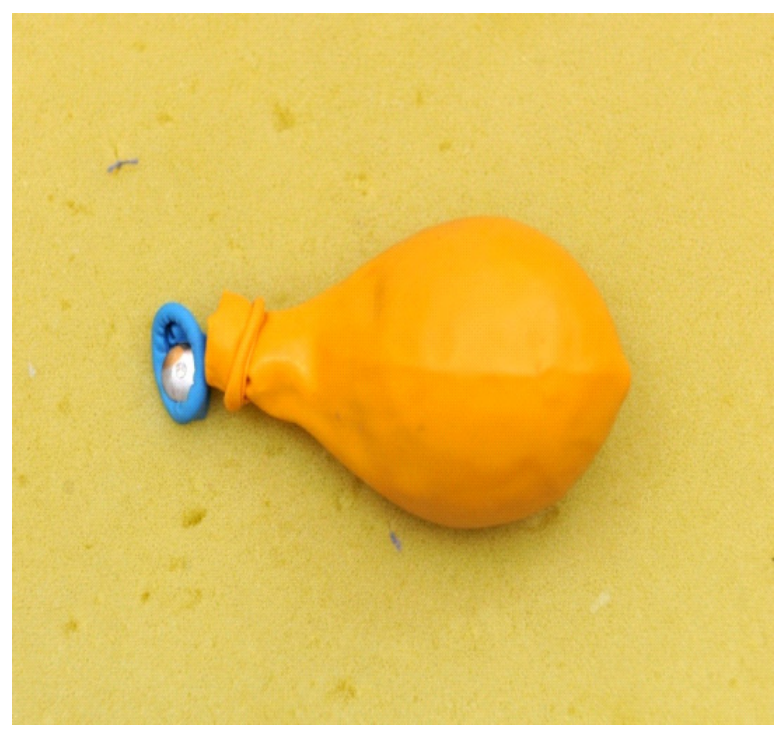

Figure 4: Ovarian cyst simulated as a balloon filled with water, which acted as an ovarian cyst, which was placed inside another balloon simulating an ovarian tissue 
Day two involved tasks learnt on day one in dry laboratory. Furthermore, participants practiced in performing laparoscopic salpingectomy and salpingostomy for ectopic pregnancy. To simulate that, we placed a date in the fallopian tube of a female camel as to make it bulky (figure 5). Participants performed salpingectomy by using bipolar diathermy or absorbable endoloop ligature, whereas monopolar diathermy was used to perform salpingostomy. In addition, participants performed these tasks on live goats (figure 6).

Day three included interactive live link to the operating theatre and assisting in resection of stage I-II endometriosis, ovarian cystectomy, tubal ligation and ovarian drilling on real consented patients.

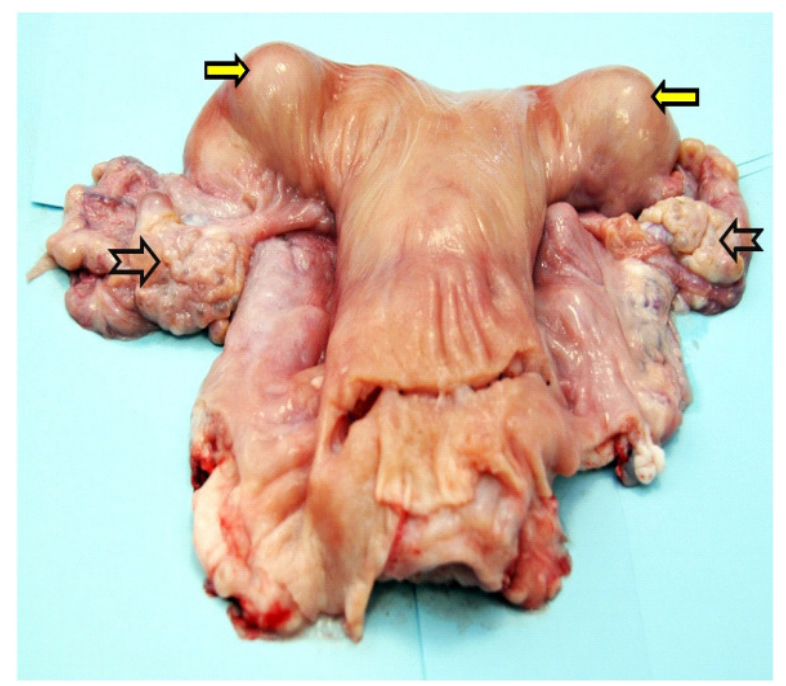

Figure 5: A camel uterus with a date inserted inside each horn (yellow arrows). Arrow heads mark both ovaries

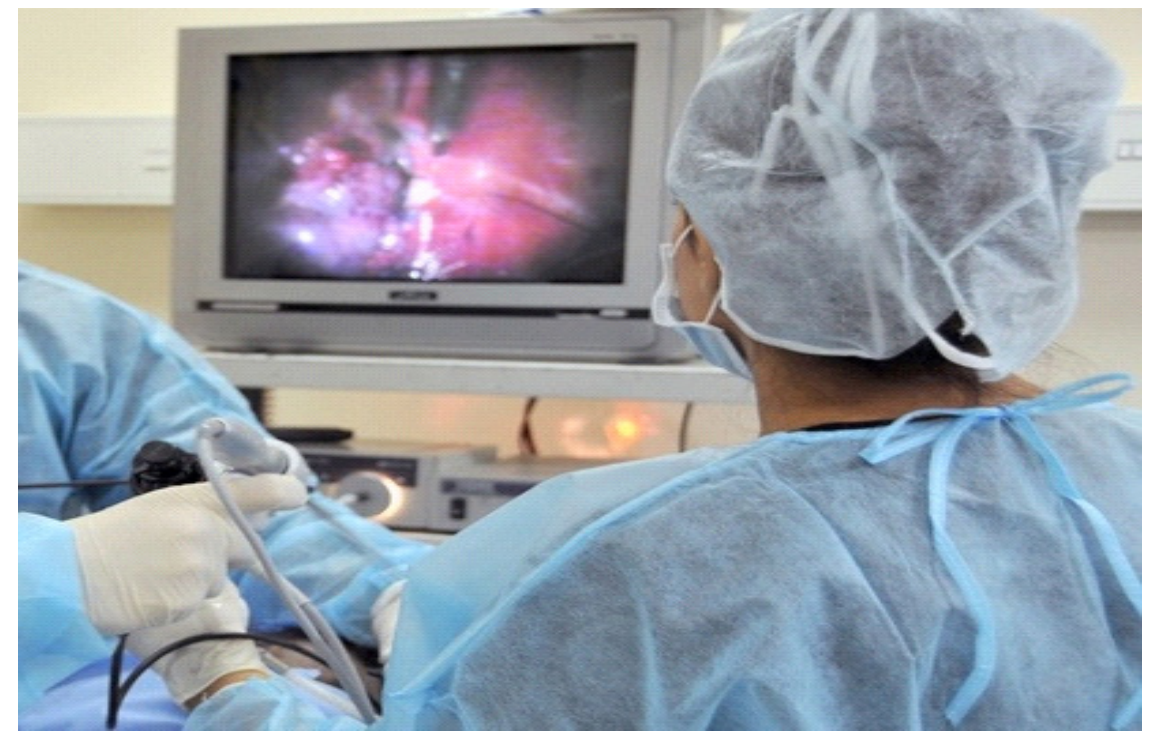

Figure 6: A participant performing salpingectomy on a live goat

\section{Evaluation of participants}

On completion of the courses, participants answered 20 multiple choice questions which were selected from the lectures. Two forms of exams were used. MCQs were written by each lecturer to cover their topics assuming the surface validity of the exam. Each consisted of 4 options. Clinical skills evaluation included performing the same tasks participants learned during the course.

\section{Course evaluation by participants}

At the end of the course, participants were requested to respond anonymously to a structured questionnaire to evaluate the course. The questionnaire consisted of 13 statements covering different aspects of the course (table 3). The participants answered each question on a four-point Likert scale $(1=$ poor, $2=$ fair, $3=$ good, $4=$ excellent). In addition, the participants answered two other questions regarding their job title and laparoscopy experience. Open ended comments were requested from the participants.

\section{Statistics}

We used the Kruskal -Wallis non-parametric statistical method to compare the ranks of the four courses and Mann Whitney U test to compare two independent groups. This is advised because the numbers of the groups were small and the response to the statements in the questionnaire was ordinal data. It is advised to use non-parametric statistical methods in this situation because a normal distribution is not needed. ${ }^{6}$ Spearman rank 
correlation was used to study the correlation between ordinal data and continuous data while linear regression was used to study the correlation between the overall MCQ and practical marks because both had a normal distribution. The reliability of individual questions was tested using the point biserial coefficient. If it was low $(<0.2)$ or negative, then these questions were revised. The Cronbach Alpha Coefficient was used to test the reliability of the MCQ exam and the questionnaire. Probabilities of less than 0.05 were considered significant. Data were analyzed with the PASW Statistics 18, SPSS Inc, USA.

\section{Results}

In total, fifty-five participants attended four courses from all Emirates of the United Arab Emirates. All participants completed the practical evaluation, MCQs and course evaluation. Thirty two out of 55 were specialists, 13 house medical officers, 6 residents and 4 consultants. Fourteen participants had no laparoscopic experience, 35 had experience at level I and six had experience at level II. None of the participants had experience at level III or IV. There was a highly significant correlation between the level of seniority and the laparoscopic experience level $(\mathrm{p}<0.0001, \mathrm{r}=0.62$, Spearman rank correlation).

All participants passed the clinical skills exam and 54 passed the MCQ exam at the end of the courses. One MCQ exam had a Cronbach Alpha Coefficient of 0.34. It had three questions with a negative point biserial coefficient and these will be removed from future exams. The second MCQ exam had a Cronbach Alpha Coefficient of 0.76 .

Only one participant failed the MCQ examination, however the participant passed the overall examination. The mean score for MCQs for all courses was $72 \%$ (range $=33-93$ ), and the mean clinical skills score was $77 \%$ (range $=55-97)$. There was a significant linear correlation between MCQs and clinical skills score $(\mathrm{p}=0.04, \mathrm{~F}=4.4$, linear regression).

There was a statistically significant difference of the MCQ mark between the three levels of experience (median (range) MCQ marks of 65 (3387), 73 (60-93), 74 (60-87), No experience, Level I experience and level II experience respectively, $\mathrm{p}=$ 0.05, Kruskal Wallis test) (figure 7) but not for the practical part (median (range) practical marks of 80 (55-95), 75 (55-97), 75 (65-85), No experience, Level I experience and level II experience respectively, $\mathrm{p}=$ 0.9, Kruskal Wallis test).

Table 3 shows the perception of the participants regarding the course. The Cronbach Alpha for the questionnaire was very high. 0.952 for all items excluding the global evaluation and 0.956 including the global evaluation

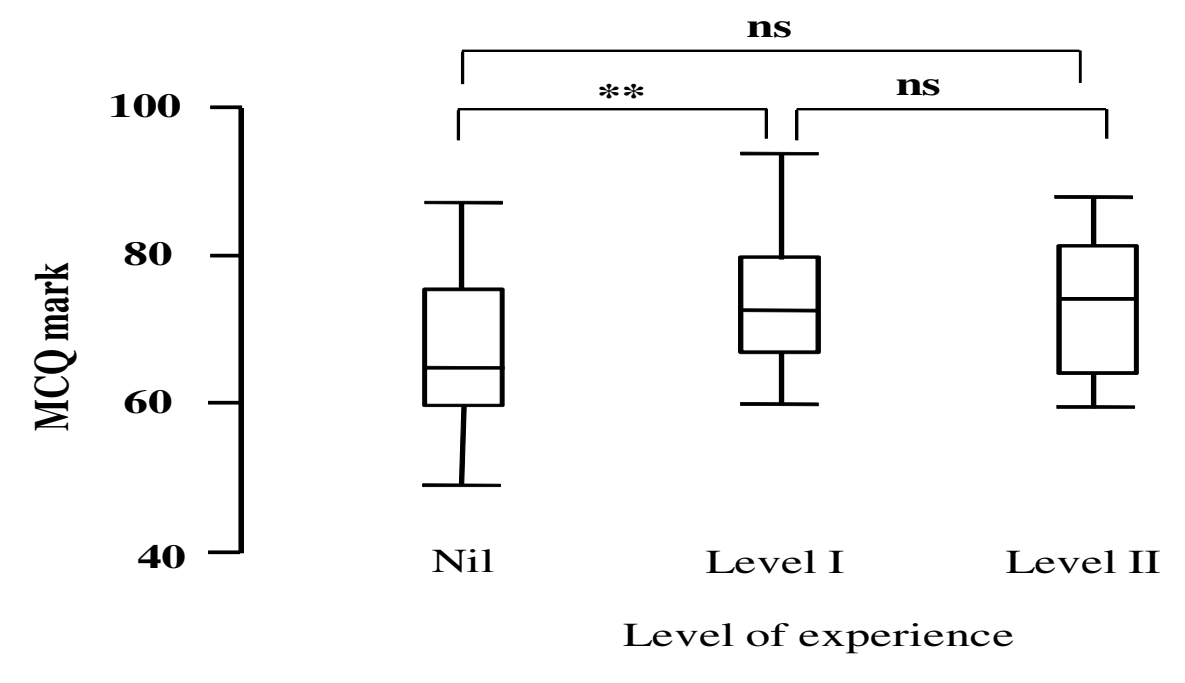

Figure 7: Box plot of the MCQ marks of the three laparoscopic experience level groups. ** $\mathrm{p}<0.02$ 
Table 3: The perception of the participants regarding the course

\begin{tabular}{|c|c|c|c|c|c|c|c|c|c|}
\hline \multirow[t]{2}{*}{ Attribute } & \multicolumn{2}{|c|}{$\begin{array}{c}\text { First course } \\
\mathrm{n}=13\end{array}$} & \multicolumn{2}{|c|}{$\begin{array}{c}\text { Second course } \\
\mathrm{n}=14\end{array}$} & \multicolumn{2}{|c|}{$\begin{array}{c}\text { Third course } \\
\mathrm{n}=14\end{array}$} & \multicolumn{2}{|c|}{$\begin{array}{c}\begin{array}{c}\text { Fourth course } \\
\mathrm{n}=14\end{array} \\
\end{array}$} & \multirow[t]{2}{*}{$p$ value } \\
\hline & Median & Mean & Median & Mean & Median & Mean & Median & Mean & \\
\hline 1. Objectives reached & $4(3-4)$ & 3.79 & $4(3-4)$ & 3.69 & $4(3-4)$ & 3.79 & $4(2-4)$ & 3.43 & 0.27 \\
\hline 2. Overall organization & $4(3-4)$ & 3.79 & $4(3-4)$ & 3.69 & $4(3-4)$ & 3.79 & $4(2-4)$ & 3.64 & 0.090 \\
\hline 3. Amount of knowledge & $4(3-4)$ & 3.79 & $4(3-4)$ & 3.69 & $4(3-4)$ & 3.79 & $4(2-4)$ & 3.21 & 0.034 \\
\hline 4.Was stimulated to learn more & $4(3-4)$ & 3.79 & $4(3-4)$ & 3.69 & $4(3-4)$ & 3.79 & $4(2-4)$ & 3.79 & 0.84 \\
\hline 5. The venue & $4(3-4)$ & 3.79 & $4(3-4)$ & 3.69 & $4(3-4)$ & 3.79 & $4(2-4)$ & 3.50 & 0.50 \\
\hline 6. The facilities & $4(3-4)$ & 3.79 & $4(3-4)$ & 3.69 & $4(3-4)$ & 3.79 & $4(2-4)$ & 3.50 & 0.50 \\
\hline $\begin{array}{l}\text { 7. Was the course helpful for } \\
\text { your daily work in the hospital- } \\
\text { Theoretical Part }\end{array}$ & $4(3-4)$ & 3.64 & $4(3-4)$ & 3.69 & $4(3-4)$ & 3.86 & $4(2-4)$ & 2.93 & 0.0001 \\
\hline $\begin{array}{l}\text { 8. Was the course helpful for } \\
\text { your daily work in the hospital- } \\
\text { Practical Part }\end{array}$ & $4(3-4)$ & 3.79 & $4(3-4)$ & 3.77 & $4(3-4)$ & 3.71 & $4(2-4)$ & 3.29 & 0.103 \\
\hline 9. Dry Lab Sessions & $4(3-4)$ & 3.71 & $4(2-4)$ & 3.69 & $4(3-4)$ & 3.71 & $4(2-4)$ & 3,36 & 0.23 \\
\hline 10. Wet Lab Sessions & $4(3-4)$ & 3.71 & $4(2-4)$ & 3.77 & $4(3-4)$ & 3.64 & $4(2-4)$ & 3.64 & 0.92 \\
\hline $\begin{array}{l}\text { 11. Live Animal Surgery } \\
\text { Session }\end{array}$ & $4(3-4)$ & 3.71 & $4(2-4)$ & 3.62 & $4(3-4)$ & 3.57 & $4(2-4)$ & 3.57 & 0.9 \\
\hline $\begin{array}{l}\text { 12. Performing laparoscopic } \\
\text { skills on patients }\end{array}$ & $4(3-4)$ & 3.71 & $4(3-4)$ & 3.62 & $4(3-4)$ & 3.64 & $4(2-4)$ & 3.50 & 0.84 \\
\hline 13. Overall rating of the course & $4(3-4)$ & 3.86 & $4(3-4)$ & 3.85 & $4(3-4)$ & 3.93 & $4(2-4)$ & 3.79 & 0.91 \\
\hline
\end{tabular}

Overall organization, amount of knowledge, stimulation to enhance learning, venue, facilities, theoretical part, practical part, dry lab sessions, wet lab sessions, live animal surgery sessions and live transmission from the hospital were highly ranked. The mean score for overall assessment of the courses was 3.8 out of 4 , which was same for all courses. There was no statistical significant difference between the overall rating of the four courses $(p=0.91$, Kruskal-Wallis test). Nevertheless, there was statistical significant different in the amount of knowledge and theoretical part between the 4 courses with course 4 having the lowest rank of all $(\mathrm{p}=0.03$, Kruskal-Wallis test). The participants of the fourth course found that the theoretical part was not useful for their daily practice ( $\mathrm{p}<0.01$, Kruskal -Wallis test). The participants suggested to include more wet lab, more animal surgery sessions, more time to be dedicated to instruments assembly and recognition, more suturing sessions, and more supervision in practical sessions so as to improve the course.

\section{Discussion}

To the best of our knowledge, our course is one of very few courses to offer comprehensive multimodality laparoscopy supplemented with theoretical presentation, practice in dry and wet laboratory, and practical experience in a live animal laboratory and assisting in performing laparoscopic skills on real patients.

In recent years, laparoscopic gynaecological surgery has been preferred for some gynaecological procedures. Gynaecological surgery requires skills such as hand-eye coordination, camera navigation, handling the instruments without tactile feedback and fine motor skills to deal with fulcrum effect and the lever forces of the long instruments.

Live operating theatres should not be the place to start learning surgical skills but rather to consolidate them. Gynaecologists should reach competency before operating on a live patient. This may be achieved by training on dry and wet laboratory. Assessment of trainees at the end of a laparoscopic course should cover both knowledge and skills.

In our study, we used MCQs and clinical skill tasks for assessment. MCQ testing appears to be the most efficient form of written assessment, being both reliable and valid because it can properly cover the content taught. Moreover, to enhance the validity of MCQ assessment, practical methods should be included as well. ${ }^{7}$ There have been several models that describe the assessment technique of the skills acquired during short laparoscopic courses. Molinas et al (2008) and Campo et al (2010) 
developed a laparoscopic skills testing and training (LASTT) model and performed two studies evaluating its feasibility and the construct validity. This included three different exercises, camera navigation, camera navigation and forceps handling and forceps handling and bi-manual coordination, specifically selected to test and train laparoscopic psychomotor skills (LPS). Results of these studies have shown that LASTT model is cost-effective for providing a continuous training and evaluation., ${ }^{8,9}$

Our course was accredited by the European Society of Endoscopic surgery. LASTT model focuses on camera navigation, hand-eye coordination and bimanual coordination which can be used as a tool for training and evaluation of laparoscopic psychomotor skills (LPS). However, LASTT model doesn't train or assess any laparoscopic procedure. In our course, we used different models to demonstrate both LPS and perform relevant gynaecological laparoscopic procedures.

Both studies by Molinas and Campo aimed to evaluate the feasibility and constructed validity of LASTT, however, our study aimed to report our modified teaching methods using compressive multimodality (theoretical presentation, practice in dry and wet laboratory and practical in a live animal model).

In our study, there was no difference in the practical performance between participants with different level of experience. Schreuder et al found significant difference between no-experienced and experienced laparoscopic participants in performing six different laparoscopic exercises. Novice or non-experienced participants were students. ${ }^{10}$ There were no level III or IV among our participants which may explain our findings. Kolkman et al found that novices reached the experts' skills level in all tasks after seven trials. ${ }^{11}$ We did not test the progress performance of the participants during the course, all participants at different levels performed well in the practical assessment. There was a significant correlation between the total MCQs mark and the total clinical skills mark.

The level of the knowledge reflected by the MCQ depended on the level of laparoscopic experience as those with less experience had the lowest MCQ mark. The low Cronbach Alpha Coefficient of the MCQ exams can be attributed to different factors including the small number of MCQs, the high homogeneity of the group, and the difficulty of the exam. ${ }^{12}$
Interestingly, there was no statistically difference between the groups in the practical mark, although, those with less experience had higher mark in the practical section. Novice learners may accept new methods of training in a smooth and quicker way compared with more experienced surgeons who have their own approach to solve problems which may be different from those taught. This may explain why participants with no experience had scored higher in the practical section and less in the MCQ. Condous et al found in a prospective observational study that inexperienced participants benefit the most from skills training. ${ }^{13}$ In contrast, Schreuder et al found that all participants at different levels of experience were satisfied by the exercises performed during laparoscopy courses. ${ }^{10}$

Overall, the participants highly ranked our course. The evaluation of laparoscopy courses by participants might be influenced by many factors. ${ }^{14}$ Less experienced surgeons tend to be polite or feel obligated to fill in the course questionnaire in exchange for a chance to "play" with the simulator, this factor may be difficult to measure. In addition, less experienced laparoscopists might give positive response to the questionnaire because they have been exposed to new experience. More experienced laparoscopists may be more critical in their opinion on laparoscopic courses. Someone might argue that all participants of our courses had no laparoscopic experience, or had level I or II laparoscopy experiences which might reflect the high ranking of our courses.

The use of animals for laparoscopy training may be restricted due to ethical and religious considerations; therefore, only few courses offer hands-on training on animals. Using animals in our courses is possibly another explanation for the high ranking of our courses. This finding is consistent with others. ${ }^{15}$

We have used a 4 points scale for two reasons. We thought that the participants may not be experienced, and it would be more proper to have a coarse grade than a more precise one. Furthermore, we avoided having 5 or 7 Likert points so as not to have a central tendency in the evaluation. In our study, all participants, independent of the level of experience, equally valued theoretical and practical parts of our courses.

It is difficult to know why the participants of the fourth course thought that knowledge and theoretical parts were not useful. It is possible that our previous courses have raised the knowledge on gynaecological 
laparoscopy and these participants had the knowledge but enjoyed the practical part.

We used training boxes in the dry lab which are inexpensive and provide training opportunities in developing countries. Moreover, expensive training modality such as virtual reality may not have additional value over traditional box trainer in laparoscopic suturing training. ${ }^{16}$

\section{Limitations of our study}

One of the limitations of our study is that we did not check how many participants could perform the exercises before the course, and how many acquired those skills after the course. Ideally, either pre-test or control group should have been used to prove that our course has actually increased the knowledge and practical skills of the participants. Nevertheless, we tested the final practical skills of the participants.

We did not collect data on the age of the participants and there were only two male participants. This did not permit us to study the effect of age or perform any reliable statistical analysis to explore the effect of gender on the perception of the participants.

The final aim of laparoscopy course is to enhance the competency and performance of the participants in the operating theatre. ${ }^{17,18}$ Our study did not address this issue. This is an important area that needs to be further studied in our setting so as to evaluate the effect of our courses on the daily clinical practice in the United Arab Emirates.

\section{Future development of the course}

We recommend that trainees who have no experience before attending the course to perform certain number of procedures under supervision before independently performing these procedures. The limited number of clinical cases available for the half day operating theatre session does not give good opportunity for hand-on training for all participants. Therefore, we plan to replace this session with wet laboratory and live animal surgery session. That will give participants the opportunity to practice more on specific laparoscopic operative skills.

One of the reasons for decrease of skills learned during the course is the time between attending the course and the start of performing procedures leaned during the course..$^{19}$ Follow up preceptor or mentorship programs may encourage those who attended the courses to incorporate procedures they learned into their practice. ${ }^{20,21}$

\section{Conclusion}

We have shown that a multimodality non expensive course for teaching gynaecological laparoscopy was highly successful in United Arab Emirates. Models used may be useful for training gynaecological laparoscopy in developing countries. The long term effects of our courses on clinical practice have yet to be evaluated.

\section{Acknowledgments}

The authors would like to thank Associate Professor Fawaz Torab, Department of Surgery, Faculty of Medicine and Health Sciences, United Arab Emirates University, Al Ain, UAE for his support and precious advice during the initial stages of establishing our courses.

\section{References}

1. Medeiros LR, Fachel JM, Garry R, Stein AT, Furness S. Laparoscopy versus laparotomy for benign ovarian tumours. Cocbrane Database Syst Rev. 2005;3:CD004751.

2. Lehmann KS, Ritz JP, Maass H, Cakmak HK, Kuehnapfel UG, Germer CT, Bretthauer G, Buhr HJ. A prospective randomized study to test the transfer of basic psychomotor skills from virtual reality to physical reality in a comparable training setting. Ann Surg. 2005; 3:442-449.

3. Derossis AM, Fried GM, Abrahamowicz M, Sigman HH, Barkun JS, Meakins JL. Development of a model for training and evaluation of laparoscopic skills. Am J Surg. 1998; 6: 482-487.

4. Katz R. Methods of training using pelvic trainers. Curr Urol Rep. 2006; 2:100-106.

5. Royal College of Obstetricians and Gynaecologists (RCOG). Classification of laparoscopic procedures per level of difficulty. Report of the RCOG working party on training in gynaecological endoscopic surgery. 2001.

6. Munro BH. Selected nonparametric techniques. In Munro, B.H., editor. Statistical methods for health care research. 4th ed. New York: Lippincott. 2001; 97-121.

7. McCoubrie P. Improving the fairness of multiple-choice questions: a literature review. Med Teach. 2004; 8:709-712.

8. Molinas C R, Win G, Ritter O, Keckstein J, Miserez M, Campo R. Feasibility and construct validity of a novel laparoscopic skills testing and training model. Gynecol Surg. 2008 ; 4: 281-290. 
9. Campo R, Reising C, Belle V Y, Nassif J, O'Donovan P, Molinas C R. A valid model for testing and training laparoscopic psychomotor skills. Gynecol Surg. 2010; 7:133-141.

10. Schreuder HW, van den Berg CB, Hazebroek EJ, Verheijen RH, Schijven MP. Laparoscopic skills training using inexpensive box trainers: which exercises to choose when constructing a validated training course. BJOG. 2011; 13:15761584.

11. Kolkman W.Wolterbeek, R. \& Jansen FW. Gynecological laparoscopy in residency training program: Dutch perspectives. Surg Endosc. 2005; 11:1498-1502.

12. Ary D, Jacobs LC, Razavieh A. Validity and reliability. In Ary D, Jacobs LC, Razavieh A (eds). Introduction to research in education. Wasdsworth/Thomson Learning, Belmont, CA, 2002. p: 241-247.

13. Condous $G$, Alhamdan D, Bignardi T, VAN Calster B, VAN Huffel S, Timmerman D, Lam A. The value of laparoscopic skills courses. Aust N Z J Obstet Gynaecol. 2009; 3:312-315.

14. Schijven M, Jakimowicz J. Face-, expert, and referent validity of the Xitact LS500 laparoscopy simulator. Surg Endosc. 2002; 12:1764-70.

15. Stovall DW, Fernandez AS, Cohen,SA. Laparoscopy training in United States obstetric and gynecology residency programs. JSLS. 2006; 1:11-15.
16. Botden SM, Torab F, Buzink SN, Jakimowicz JJ. The importance of haptic feedback in laparoscopic suturing training and the additive value of virtual reality simulation. Surg Endosc. 2008; 5:1214-1222.

17. Traxer O, Gettman MT, Napper CA, Scott DJ, Jones DB, Roehrborn CG, Pearle MS, Cadeddu JA. The impact of intense laparoscopic skills training on the operative performance of urology residents. J Urol. 2001; 5:1658-1661.

18. Stefanidis D, Korndorffer JR Jr, Black FW, Dunne JB, Sierra R, Touchard CL, Rice DA, Markert RJ, Kastl PR, Scott DJ. Psychomotor testing predicts rate of skill acquisition for proficiency-based laparoscopic skills training. Surgery. $2006 ; 2: 252-262$.

19. Colegrove PM, Winfield HN, Donovan JF Jr, See WA. Laparoscopic practice patterns among North American urologists 5 years after formal training. J Urology 1999; 161: 881-886.

20. Heniford BT, Matthews BD, Box EA, Backus CL, Kercher KW, Greene FL, Sing RF. Optimal teaching environment for laparoscopic ventral herniorrhaphy. Hernia: the journal of hernias and abdominal wall surgery.2002; 6: 17-20.

21. See WA, Cooper CS, Fisher RJ. Predictors of laparoscopic complications after formal training in laparoscopic surgery. JAMA.1993; 270: 26892692. 